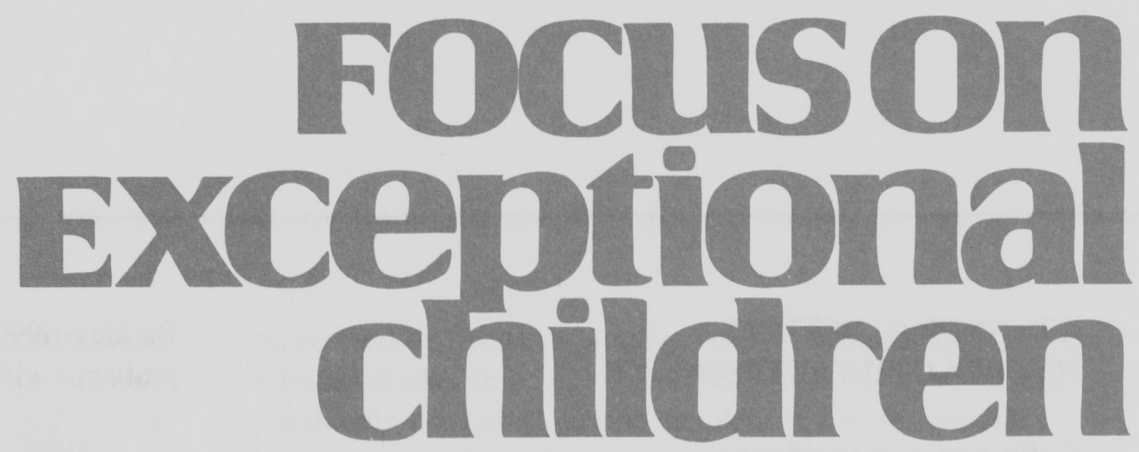

\title{
Common Pediatric Disabilities: Medical Aspects and Educational Implications
}

\author{
Janet Siantz Tyler and Steven Colson
}

The recent movement to include students with disabilities in general education classrooms poses a variety of challenges to school personnel. Many classrooms are now accommodating a wider variety of diversity, including a significant group of students with complex medical disorders (Smith \& Luckasson, 1992; Stainback \& Stainback, 1989). Successful inclusion of these students will depend on educators having a more comprehensive understanding of these disabilities and learning to collaborate with medical personnel.

Advances in medical technology have changed the course for students in several ways. For example, it has dramatically increased the survival rate of at-risk neonates, as well as reduced the risk of life-threatening complications commonly associated with many disabilities (Brown, 1993; Goldson, 1993; Warshaw, 1992). In addition, major progress has been made in the ability to determine the etiology of many disorders, and associated research has provided insights into multidisciplinary treatments and interventions. As these medical advances continue, more and more children with disabilities will be entering the general education classroom. It is imperative, therefore, that educators possess current information and the skills necessary to collaborate effectively with medical and ancillary personnel.

This article provides a brief overview of common pediatric disabilities and their implications for educators. An increased understanding of these disabilities will enable educators to explain the child's disability to parents and general education teachers, to make appropriate referrals for students who have not been identified, and to facilitate the assessment process and thereby achieve more appropriate programming.

In this article each disability is defined, and current information about incidence and causes is summarized. Diagnosis is also discussed, including common characteristics. The complications section covers information about associated deficits in the cognitive, language, motor, behavioral, and academic areas. Finally, multidisciplinary intervention approaches are described and a list of resources for obtaining additional information is provided.

Janet Tyler is director of the Traumatic Brain Injury Project, Department of Special Education, University of Kansas Medical Center. Steven Colson is a courtesy assistant professor in the Department of Special Education at the University of Kansas Medical Center. 


\section{ATTENTION DEFICIT HYPERACTIVITY DISORDER}

\section{Definition and Incidence}

Despite the recent explosion of information and interest surrounding attention deficit hyperactivity disorder (ADHD), this disorder has actually been documented in the medical literature for over 90 years (Still, 1902), during which time it has been known by a variety of names. Recently, a consensus definition was proposed:

Attention Deficit Hyperactivity Disorder is a developmental disorder characterized by developmentally inappropriatedegrees of inattention, overactivity, and impulsivity. These often arise in early childhood; are relatively chronic in nature; and are not readily accounted for on the basis of gross neurological, sensory, language, or motor impairment, mental retardation, or severe emotional disturbance. These difficulties are typically associated with deficits in rule-governed behavior and in maintaining a consistent pattern of work performance over time. (Barkley, 1990, p. 47)

\section{Focuson
Exceptional children}

ISSN 0015-511X

FOCUS ON EXCEPTIONAL CHILDREN (USPS 203-360) is published monthly except June, July, and August as a service to teachers, special educators, curriculum specialists, administrators, and those concerned with the special education of exceptional children. This publication is annotated and indexed by the ERIC Clearinghouse on Handicapped and Gifted Children for publication in the monthly Current Index to Journals in Education (CIJE) and the quarterly index, Exceptional Children Education Resources (ECER). The full text of Focus on Exceptional Children is also available in the electronic versions of the Education Index. It is also available in microfilm from Xerox University Microfilms, Ann Arbor, MI. Subscription rates: Individual, $\$ 30$ per year; institutions, $\$ 40$ per year. Copyright (C) 1994 , Love Publishing Company. All rights reserved. Reproduction in whole or part without written permission is prohibited. Printed in the United States of America. Second class postage is paid at Denver, Colorado. POSTMASTER: Send address changes to:

Love Publishing Company

Executive and Editorial Office

1777 South Bellaire Street

Denver, Colorado 80222

Telephone (303) 757-2579

Edward L. Meyen

University of Kansas

Richard J. Whelan

University of Kansas Medical Center tanley F. Love

Publisher
Glenn A. Vergason Georgia State University

Holly T. Rumpler Senior Editor
Barkley (1990) has proposed his own definition focusing on problems with rule-governed behavior:

\begin{abstract}
ADHD consists of developmental deficiencies in the regulation and maintenance of behavior by rules and consequences. These deficiencies give rise to problems with inhibiting, initiating, or sustaining responses to tasks or stimuli, and adhering to rules or instructions, particularly in situations where consequences for such behavior are delayed, weak, or nonexistent. The deficiencies are evident in early childhood and are probably chronic in nature. Although they may improve with neurological maturation, the deficits persist in comparison to same-age normal children, whose performance in these areas also improves with development. (p. 71)
\end{abstract}

It is important for teachers to remember that neither the Individual with Disabilities Education Act (IDEA) or Section 504 of the Rehabilitation Act contains a federal definition for ADHD. Currently, therefore, students who have the diagnosis of $\mathrm{ADHD}$ and whose education in the general education class is negatively impacted can receive special services under the educational classification of Other Health Impaired (U.S. Department of Education, 1991).

Because of imprecision in definition and criteria, it is difficult to accurately measure the incidence of ADHD. The consensus of opinion seems to fall between $3 \%$ and $5 \%$ of the childhood population (American Psychiatric Association, 1987), although estimates vary from $1 \%$ to $20 \%$ (Ross \& Ross, 1982; Szatmari, Offord, \& Boyle, 1989). Considerably more males than females appear to be diagnosed with ADHD, anywhere from 2:1 to 10:1 (American Psychiatric Association, 1980; Ross \& Ross, 1982). It is unclear whether this significant variation between the sexes stems from developmental, biological, or cultural factors.

\section{Cause}

A growing body of evidence suggests that ADHD stems from neuroanatomical, neurochemical, and neurophysiological differences (Riccio, Hynd, Cohen, \& Gonzalez, 1993). One hypothesis concerns differences in the frontal lobes, basal ganglia, and brain stem. Another focuses on problems with one of the major transmitter systems or some specific right hemisphere dysfunction. Further, according to a recent theory, a disruption "in certain ascending/arousal and descending/inhibitory pathways (e.g., the loops that connect the frontal lobes, basal ganglia, and thalamus) that constitute a system which activates/inactivates other brain regions" is seen as a probable cause (Riccio et al., 1993, p. 121). This disruption may result in problems with inhibition and selective attention. 
ADHD may also result from hereditary predisposition or acquired brain injury. There is little empirical support to indicate that ADHD is caused by social/environmental factors, diet, or parental management, although these variables may exacerbate an existing condition (Barkley, 1990).

\section{Characteristics}

The Diagnostic and Statistical Manual for Mental Disorders - Fourth Edition (American Psychiatric Association, 1994) has changed the way ADHD is diagnosed and subtyped. This set of criteria now differentiates individuals who have symptoms of inattention from those with symptoms of hyperactivity and impulsivity (some individuals may meet the criteria for both subtypes). Because IDEA and Section 504 do not include criteria for ADHD, this well-respected, professionally developed set of standards may be particularly useful for schools in conducting an assessment.

\section{Associated Complications}

Although most children with ADHD demonstrate some degree of cognitive, academic, behavioral, and social problems, some may also concomitantly exhibit specific learning disabilities or behavior disorders. Estimates suggest that $25 \%$ of children with ADHD may have co-occurring learning disabilities. Considerably more children (20\% to $60 \%)$ are diagnosed with oppositional defiant disorder or conduct disorder and may receive special education services under the classification of behavior disorders.

Conflicting information exists about concomitant speech and language delays. Some studies indicate problems in expressive language (Munir, Biederman, \& Knee, 1987; Szatmari et al., 1989), whereas others have found no differences in these areas between ADHD and non-ADHD children (Barkley, 1990). Also, although no evidence linking sensory development to ADHD exists, there may be an increased incidence of middle ear infections (Mitchell, Aman, Turbott, \& Manku, 1987).

\section{Interventions}

Because there is no cure for ADHD, current treatment focuses on minimizing the disability's symptomatology (Fowler, 1992), usually through a combination of medical, educational, psychological, behavioral, and parental interventions. The chance for success increases when a multimodal approach is followed.

Since the 1950s psychostimulant medications have been used successfully to treat ADHD. Although most beneficial with school-age children, recently medications have been prescribed for increasing numbers of individuals throughout adulthood (Accardo, Blondis, \& Whitman, 1991). The most commonly prescribed psychostimulant is Ritalin, with Dexedrine and Cylert usually the secondary choices.

Tricyclic antidepressants are prescribed especially when a child either does not respond to a psychostimulant or has an adverse reaction to this type of medication. Commonly prescribed antidepressants include Tofranil and Norpramin. Clonodine, a drug originally developed as an antihypertensive, is more rarely prescribed. However, Clonodine is usually recommended when the student has a concomitant diagnosis of Tourette syndrome.

Educational modifications are usually necessary for students with ADHD. For example, because of their difficulty in selective and sustained attention, they may require closer proximity to the teacher or the use of a peer tutor or paraprofessional. Also, reduction in independent seatwork and homework can relieve stress for the student, teachers, and parents alike.

Routine is important to students with ADHD. Classroom environments need to be carefully planned and organized, with changes directly communicated to the student in advance. Students should be seated away from distractors, and transitions between activities need to be carefully monitored and practiced. A knowledgeable and caring teacher is a crucial factor- one who is structured but can also sense the need to relax rules and modify classroom assignments when in the child's best interest.

Teaching self-monitoring strategies to students with ADHD is often very effective. Students need not only classroom modifications but also specific training in developing strategies to aid them in maintaining attention and monitoring impulsive behaviors inside and outside of school. Social skills training (e.g., how to accept criticism and praise appropriately, make and keep friends, interrupt others appropriately, take turns in games and conversation, read others' facial and vocal inflection cues) is particularly beneficial to most ADHD children. Unfortunately, few students with ADHD have these goals on their individual education plan and few educators have received specific training in how to teach these skills.

Parent training is also a crucial part of a comprehensive treatment plan. Parents need information about the effects and limitations of medication and may need to be taught how to take appropriate baseline and post-treatment data for the physician (educators may need the same training). A child with ADHD affects the whole family, most often negatively before treatment is sought. Educators can be an important resource for parents in continuing a successful and consistent behavior management approach begun at school. Support groups can be valuable as well, especially those that offer 
parents the opportunity to share successful strategies with one another.

\author{
Resources \\ CHADD (Children and Adults with Attention \\ Deficit Disorder) \\ 1859 North Pine Island Rd., Suite 185 \\ Plantation, FL \\ (305) 384-6869
}

\section{CEREBRAL PALSY}

\section{Definition and Incidence}

The term cerebral palsy (CP) is used to describe a group of chronic nonprogressive conditions characterized by abnormalities in motor function involving strength, tone, posture, or coordination. There are three main types of CP: spastic, athetoid, and ataxic. Spastic CP (the most frequent) is characterized by stiff or difficult movement. Athetoid CP involves involuntary and uncontrolled movements, and ataxic CP is characterized by unsteadiness and difficulty with rapid or fine movements. Some individuals have a mixture of all three types of CP (United Cerebral Palsy Associations, 1993).

Most recent studies have estimated the prevalence of CP to be 2 per 1,000 live births (Shapiro \& Capute, 1994). The risk of $\mathrm{CP}$ is increased in low birth weight babies (less than 2500 g) (Cummins, Nelson, Grether, \& Velie, 1993) and twin pregnancies (Grether, Nelson, \& Cummins, 1993). With increases in survival rates of premature infants and increased numbers of multiple births, educators are likely to be providing services for a growing number of children with $\mathrm{CP}$.

\section{Causes}

Cerebral palsy results from a central nervous system (CNS) injury or anomaly that occurs in the early period of brain development. The majority of cases of $\mathrm{CP}$ are congenital, with problems during intrauterine development accounting for the majority of known causes (Naeye, Peters, Bartholomew, \& Landis, 1989). Approximately $10 \%$ or less of cases are considered to be acquired. The majority of acquired cases are due to head trauma and infections of the brain.

Hagberg and Hagberg (1984) divided the most common antecedents that place a child at risk for $\mathrm{CP}$ into events that take place during (a) the prenatal period, (b) labor/delivery, (c) the perinatal period, and (d) childhood. Events that take place in the prenatal period include exposure to teratogens, genetic syndromes, chromosomal abnormalities, brain mal- formations, intrauterine infections, and problems in fetal/placental functioning. Complications of labor and delivery are risk factors, although not as significant as traditionally thought. During the perinatal period, sepsis/CNS infections, asphyxia, and prematurity are the major risk factors, whereas brain infections, traumatic brain injury, and ingestion of toxins are the major risk factors during childhood. It is important to note that not all children with these risk factors develop $\mathrm{CP}$, and approximately one fourth of all cases of $\mathrm{CP}$ have no definable cause (Eicher \& Batshaw, 1993).

\section{Characteristics}

$\mathrm{CP}$ is characterized by an inability to fully control motor function, particularly muscle control and coordination. Because there is no specific test to diagnose $\mathrm{CP}$, the condition is diagnosed by excluding other neurologic conditions. It is impossible to diagnose $\mathrm{CP}$ in the neonatal period by clinical methods, and it is often difficult to diagnosis CP in the first 6 months of life because the earliest signs of CP are subtle. During the 6- to 18-month period, motor delay is the basis for diagnosis of CP. The physician looks for abnormalities in muscle tone, deep tendon reflexes, the persistence of primitive reflexes, lack of normal postural responses, and asymmetries (Shapiro \& Capute, 1994). Confounding the diagnosis of $\mathrm{CP}$ is the fact that not all of these abnormalities are present in every in child with CP. Further, signs typically characteristic of CP may be found in the infant and then disappear at a later age (Golden, 1987).

\section{Associated Complications}

CP rarely occurs without associated deficits (Shapiro \& Capute, 1994). In addition to movement and posture disorders, children with CP may have other disabilities associated with damage to the CNS. For example, approximately twothirds of the children with $\mathrm{CP}$ have mental retardation, and among those with normal intelligence, many have some degree of perceptual impairment and learning disability (Kurtz, 1992). Other common associated deficits include seizures, sensory deficits, communication disorders, feeding problems, and behavioral/emotional disturbances (e.g., attentional deficits and impulsivity).

\section{Interventions}

Because of the multitude of problems associated with $\mathrm{CP}$, an interdisciplinary assessment and treatment approach is necessary. Specifically, the skills of the pediatrician, neurologist, psychologist, orthopedist, ophthalmologist, occupational therapist, physical therapist, speech-language pathologist, 
special educator, and social worker are important in developing and maintaining a program for the child with $\mathrm{CP}$.

Treatment of CP is directed toward maximizing the child's functional abilities while minimizing the handicapping effects. Therefore, treatment goals aim at improving function, developing compensatory strategies, and encouraging independence (Eicher \& Batshaw, 1993). Treatment to maximize motor function should be started as early as possible (Shapiro \& Capute, 1994). Some evidence suggests that early intervention has the potential to improve the rate and quality of motor development in children with CP (Kanda, Yuge, Yamori, Suzuki, \& Fukase, 1984). However, more research is needed to identify the effective components of therapy (Turnbull, 1993).

The child's motor dysfunction requires an individualized physical therapy (PT) and occupational therapy (OT) program. Therapy focuses on preventing postural deformity and normalizing tone to permit more functional abilities while providing the child with sensorimotor experiences that enhance the development of normal movement patterns. In addition to PT and OT, orthopedic surgery may be used in some instances to increase the range of motion through the release, lengthening, or transfer of affected muscles and tendons (Kurtz, 1992). In other cases orthotic devices (e.g., braces, splints) that assist function, prevent deformity, or normalize tone may be sufficient to treat these problems (Percy, 1994). Therapy may also include the use of medication to control seizures, spasticity, and rigidity. In some instances neurosurgical approaches that alter the abnormal control of movement may be used (Shapiro \& Capute, 1994).

As the child reaches preschool age, it is important to provide not only OT and PT to treat abnormalities of tone and posture but also intervention that addresses communication, cognitive deficits, peer acceptance, and environmental issues. At this time, children with $\mathrm{CP}$ often begin to recognize that their motor dysfunction makes them different from their peers. Therefore, appropriate attention must be given to their mental health as well (Percy, 1994).

As the child enters grade school, therapy should be directed at helping the child function in school and perform activities of daily living (Eicher \& Batshaw, 1993). The child's educational placement should be based on cognitive abilities. Because the degree of involvement and severity of the condition may vary considerably, a full continuum of educational services is needed. Regardless of where the child is served, the teachers must possess a basic understanding of treatment procedures so they can reinforce desirable movements and postural habits. In the classroom, adaptive devices such as pencil holders, adapted computer keyboards, augmentative communication devices, page turners, book holders, and proper seating apparatuses may help to facilitate the child's functioning.

\author{
Resources \\ United Cerebral Palsy Associations, Inc. \\ 1522 "K" Street, NW, Suite 1112 \\ Washington, DC 20005 \\ (800) $872-5827$
}

\section{DOWN SYNDROME}

\section{Definition and Incidence}

Down syndrome (DS), or trisomy 21 , was one of the first medical conditions to be associated with mental retardation, although the chromosomal abnormality was not identified until 1959 (Shapiro, 1992). This is the most common autosomal chromosomal abnormality in liveborn infants. The frequency of occurrence is estimated to be 1 in 700 to 1 in 1,000 live births.

\section{Cause}

Down syndrome is the single most common genetic cause of mental retardation. Children with DS have three rather than two copies of chromosome 21 . There is a considerable association between advanced maternal age and DS. Thus, the risk of a 35- to 39-year-old woman having a child with Down syndrome is approximately 6.5 times that of a 20 - to 24-year-old. This figure climbs to 20.5 times for mothers between 40 and 44 years of age (Shapiro, 1992).

\section{Characteristics}

Children with DS present with hypotonia (decreased muscle tone); brachydactyly (short hands and fingers); incurving of the fifth finger; abnormal fingerprints; widely spaced nipples; single creases across the palms and soles of the feet; and cardiac, gastrointestinal, and skeletal malformations. Atypical craniofacial features include microcephaly (small, round head), brachycephaly (flat head), small, underdeveloped ears, mouth held open with large tongue protruding, obliquely placed eyes, underdeveloped iris, and excessive skin about the neck (Tunnessen, 1994). Even with these observable features, the diagnosis of Down syndrome needs to be confirmed with a chromosomal analysis.

\section{Associated Complications}

Early in the neonatal period, the child with DS appears floppy and has associated feeding problems. Gross motor 
skills are delayed, with most children not sitting until age one and not walking until they are two years old. Language skills are also considerably delayed, and children may have unusual speech patterns with articulation delays. Although many children with DS appear cognitively better early on in their development, by school age they usually appear in the mild to moderate mental retardation range with some functioning in the severe range.

\section{Interventions}

Forty percent of children with DS have congenital heart disease and gastrointestinal blockage, often requiring surgery. Virtually all children with Down syndrome have vision problems as well as hearing problems due to recurrent middle ear infections. Sixty to ninety percent may also have a mild to moderate conductive hearing loss, some requiring amplification.

All children with DS will require special education and related services, although children involved in early stimulation programs may have a greater chance of reaching their potential. In the early school years, children with DS may be more easily included with their nondisabled peers. However, most students will need intensive functional skill development as well as appropriate prevocational planning and postschool transition assistance to appropriate living arrangements.

\section{Resources}

Association for Children with Down Syndrome

2616 Martin Avenue

Bellmore, NY 11710

(516) 221-4700

\section{National Down Syndrome Congress}

1800 Dempster St.

Park Ridge, IL 60068-1146

(800) 232-6372; (708) 823-7550

National Down Syndrome Society

666 Broadway, Suite 810

New York, NY 10012

(800) 221-4602; (212) 460-9330

\section{FRAGILE X SYNDROME}

\section{Definition and Incidence}

Fragile X syndrome, which has only been discovered and researched in the last 10 to 15 years, may account for the predominance of severe mental retardation in males over fe- males. In this syndrome, the bottom tip of the $\mathrm{X}$ chromosome has been pinched off causing it to appear fragile (Shapiro, 1992). Although research in this area is in its infancy, the incidence of Fragile $\mathrm{X}$ syndrome has been estimated between 0.6 in 1,000 to 1 in 1,000 males (Sherman, 1991), and it probably represents between $6 \%$ and $14 \%$ of all males with severe mental retardation. Ten percent of boys who have been classified as having autism also have Fragile X syndrome, and 50\% of young men with mental retardation and large testicles have this disorder. Fragile X syndrome is now second to Down syndrome as the most commonly identified cause of mental retardation (Hagerman, 1987).

Until recently, it was assumed that women carried the trait but were asymptomatic; however, research is now showing that a third of the female carriers have cognitive abilities in the borderline or mild retardation ranges.

\section{Characteristics}

Males with Fragile $\mathrm{X}$ syndrome have elongated faces, prominent jaws, and long ears (Smith, 1989). Almost all have enlarged testicles and many have a prolapse of the mitral heart valve. Large head size, protruding ears, high arched palates, and narrow nasal bridges are common. As with Down syndrome, the incidence of epicanthal folds and simian creases is widespread. Further, individuals with Fragile $\mathrm{X}$ syndrome appear to be hypotonic and clumsy, with hyperextensible joints. Compared to adult men with the disorder, boys have more subtle facial changes and no testicular enlargement.

Approximately $20 \%$ of males carrying the Fragile X chromosome are asymptomatic but can transmit the trait to their children or grandchildren, who may be symptomatic. In addition, approximately $30 \%$ of carrier girls express the disorder in a milder form than do boys with the syndrome. Girls with Fragile $\mathrm{X}$ syndrome tend to have slightly dysmorphic features, and their cognitive deficits tend to range from mild-tomoderate learning disabilities to mild mental retardation. It is now believed that about $7 \%$ of mild retardation in girls can be attributed to Fragile X syndrome. Because female carriers of an $\mathrm{X}$-linked trait are found at a rate approximately double that of affected males, special education teachers can expect to find that $1 \%$ of their students will have difficulty due to Fragile X syndrome (Smith, 1989).

Fragile X syndrome can be diagnosed by chromosomal analysis although not all males who exhibit the fragile site show signs of any abnormality. Some of these individuals have normal intelligence and lack any dysmorphic features but nevertheless can transmit the gene to their daughters (Smith, 1989). 


\section{Associated Complications}

Individuals with Fragile $\mathrm{X}$ syndrome demonstrate significant cognitive, language, and behavioral deficits. Most are mentally retarded, with communication skills more delayed than cognitive and motor abilities. Their language is characterized by echolalia, perseveration, and numerous dysfluencies, including cluttering and stuttering (Wolf-Schein, Sudhalter \& Cohen, 1987). Individuals with Fragile X syndrome often have poor auditory memory skills as well as auditory perception difficulties. Furthermore, they have been reported to experience extreme difficulty in processing novel, sequential information, especially when short-term memory and flexibility in problem solving are required (Reiss \& Freund, 1990). In many cases, their IQ scores tend to decrease over time, probably due to initial overestimation of their nonverbal skills (Prouty, Rogers, \& Stevenson, 1988).

Behavior problems can include self-stimulatory behaviors (hand flapping and head banging) as well as hyperactivity and attention deficits. About $20 \%$ of persons with Fragile X syndrome have some type of seizure disorder. Some of these individuals may be more correctly characterized as having a pervasive developmental disability such as autism.

\section{Interventions}

Even children with mild dysmorphic features require special education and related services. For example, extensive language therapy is typically needed early on, with many students showing language as a relative strength by adolescence. Perceptual and cognitive deficits, however, appear to be lifelong, requiring services provided collaboratively by both a special education teacher and an occupational therapist (Theobald, Hay, \& Judge, 1987). Students with Fragile X syndrome need a behavior plan that addresses their hyperactive and impulsive behaviors. They also may require intensive social skills training. Many students respond well to routine, and educators can be helpful by translating appropriate routines to home situations.

Often these students are first identified as having a learning disability but later more appropriately fit a diagnosis of mental retardation. For this reason, students may need to be reevaluated yearly during the elementary years (Santos, 1992), and their individual education plans will need to be modified as the students mature because their social and academic skills can become more deficient over time.

\section{Resources}

The National Fragile X Foundation

1441 York Street, Suite 215
Denver, CO 80206

(800) 688-8765

\section{LEUKEMIA}

\section{Definition and Incidence}

Leukemia is "a disease of the blood-forming tissue characterized by the uncontrolled growth and proliferation of immature lymphocytes (i.e., malignant cells), with a reduction in the number of red cells and an increase in the number of white cells" (Brown \& Madan-Swain, 1993, p. 74). It is the most common cancer diagnosed in children (Mahoney, 1994).

According to Mahoney (1994), an estimated 2,000 cases of leukemia in children younger than 15 years of age occur in the United States each year. Approximately three fourths of the cases involve acute lymphoblastic leukemia (ALL); the majority of the remaining cases are acute nonlymphocytic leukemia. The peak incidence for childhood ALL in the United States is between 2 and 6 years of age. Further, childhood ALL occurs more frequently in boys than in girls, and the difference increases with age.

\section{Causes}

The cause or causes of childhood leukemia remain unknown, although a variety of environmental, genetic, viral, and immunologic factors may contribute to its development (Mahoney, 1994). For example, environmental factors (such as radiation exposure) may play a role by triggering preexisting defects (Fernbach, 1994).

\section{Characteristics}

Children with ALL present with a variety of nonspecific symptoms, most commonly including fever, pallor (paleness), purpura (purple spots on the skin caused by hemorrhages), and pain (Mahoney, 1994). The onset may be abrupt or proceed over a few days, weeks, or months. The diagnosis of ALL is established by blood and bone marrow examination.

\section{Associated Complications}

Children with leukemia are at risk for developing infections of the central nervous system such as chronic viral infections and fungal infections (Mahoney, 1994). Furthermore, bacterial infections and nonbacterial opportunistic infections (e.g., chickenpox) can cause devastating illness in children with leukemia. 
A number of short- and long-term effects of cancer treatment can also occur. Medical effects of cancer treatment include growth hormone deficiency, delayed sexual maturation, hypothyroidism, scoliosis, dental and facial abnormalities, cardiac disease, pulmonary problems, and liver and eye difficulties (Meadows \& Silber, 1985).

In addition, learning difficulties related to cranial irradiation may also appear. A number of studies have documented a high incidence of neurocognitive deficits associated with radiation therapy (Brown \& Madan-Swain, 1993). For example, Copeland et al. (1988) found that, in particular, intrathecal chemotherapy plus cranial radiotherapy was found to be associated with significant effects on neuropsychological performance. Although most researchers and clinicians in the field of pediatric oncology agree that central nervous system prophylactic treatment (CNSPT) of leukemia is clearly detrimental to cognitive and behavioral functioning at least in some children, the effects of the treatment on the neuropsychological functioning of long-term cancer survivors remains controversial. In their review of 53 studies on the effects of CNSPT on cognition and neuropsychological functioning, Butler and Copeland (1993) found no consensus regarding the neuropsychological effect of CNS prophylactic treatment in childhood cancer.

In addition to possible learning problems associated with the side effects of cancer treatment, a variety of other factors may interfere with the child's school performance. In particular, school absences and anxiety related to their disease place children with cancer at risk for underachievement in school (Copeland et al., 1988).

\section{Interventions}

With a goal of eliminating as many leukemic cells as possible and reestablishing normal cells, treatment of childhood leukemia generally consists of a combination of chemotherapy programs and central nervous system therapy (Mahoney, 1994). Central nervous system prophylactic treatment $(\mathrm{CN}-$ SPT) consists of either intrathecal chemotherapy (chemotherapy injected directly into the spinal cord), central nervous system radiation therapy (used to destroy cancer cells), or a combination. These treatments are designed to eliminate any cancerous cells and reduce the probability of CNS relapse (Butler \& Copeland, 1993). The standard duration of treatment therapy is 2 to 3 years (Mahoney, 1994).

Leukemia was once considered an incurable disease. However, remission rates now approach $90 \%$, and approximately $65 \%$ of the children newly diagnosed with ALL survive in complete continuous remission for more than 5 years and remain free of disease (Mahoney, 1994). Increasing survival rates are directly related to more potent treatments and pow- erful combinations of chemotherapy and radiation (Kazak, 1993). Because of their improved prognosis, children with leukemia present new challenges for educators.

Due to ongoing treatment or side effects, children with leukemia are often absent from school for extended periods. Therefore, a coordinated program between the hospital classroom teacher, the homebound instructor, and the school must be established. Collaboration between school officials and the health-care staff is also recommended as a means of early detection and intervention in problem areas (Copeland et al., 1988). Additionally, prior to the child's return to school, reentry planning needs to take place. School personnel who will be working with the child, as well as the child's classmates, should receive education regarding leukemia (Brown \& Madan-Swain, 1993).

At the time of re-entry the child's cognitive and behavioral status should be assessed. For example, children with leukemia who have cognitive or behavioral deficits may require some form of special education, either through classification under Other Health Impaired (OHI) or, if they meet the requirements, learning disabilities (LD). The child may also require assistance in dealing with the psychological effects of having a life-threatening illness. Counseling to learn strategies for relaxation and building self-confidence may be necessary to alleviate anxiety (Copeland et al., 1988).

Deficits resulting from treatment may be subtle and therefore not recognized immediately. Even if the child returns to school without initially experiencing any learning or behavioral problems associated with leukemia and its treatment, school personnel should develop a systematic plan for monitoring the child's educational progress. This allows school personnel to rapidly detect any problems that may arise.

\section{Resources}

AMC Cancer Information Center

1600 Pierce

Lakewood, CO 80214

(800) 525-3777

\section{NEUROFIBROMATOSIS}

\section{Definition and Incidence}

Neurofibromatosis (NF) is a genetic disorder that affects the skin and the nervous system and, in rare cases, the acoustic system. Affecting one in every 4,000 children, NF affects both sexes equally and has no particular racial, geographic, or ethnic distribution. In the United States 100,000 individuals are affected. 
NF has been classified into two types: NF-1 and NF-2 (Riccardi, 1994). NF-1 (Peripheral or von Recklinghausen $\mathrm{NF}$ ) is characterized by multiple café-au-lait spots and neurofibromas on or under the skin. Enlargement and deformation of bones and curvature of the spine may also occur. Furthermore, tumors develop in the brain, on cranial nerves, or on the spinal cord.

NF-2 (Central Bilateral Acoustic NF), a much rarer form of neurofibromatosis, is characterized by multiple tumors on the cranial and spinal nerves and by other lesions of the brain and spinal cord. Tumors affecting both of the auditory nerves are present. Hearing loss beginning in the teens or early twenties is generally the first symptom of the disease.

\section{Cause}

Both forms of NF are autosomal dominant genetic disorders that may be inherited from a parent who has NF or may be the result of a new or spontaneous mutation in the sperm or egg cell. Each child of an affected parent has a $50 \%$ chance of inheriting the gene and developing NF. The type of NF inherited by the child is always the same as that of the affected parent; however, the severity of the manifestations may differ from person to person within a family (NF Foundation, 1994).

\section{Characteristics}

The most common characteristic of NF is tumors, called neurofibromas, that typically develop on or just underneath the surface of the skin but may also occur in deeper areas of the body. These tumors usually develop around puberty, but may appear at any age. The tumors are not contagious but can be very disfiguring.

Another common sign of NF is the presence of flat, pigmented spots on the skin, which are called by the French term for coffee with milk (café au lait) because of their light tan color. In darker-skinned people, café-au-lait spots appear darker in color than surrounding skin.

A diagnosis of NF typically involves the presence of six or more café-au-lait spots. Fewer café-au-lait spots may occur in people who do not have NF; in fact, about $10 \%$ of the general population have one or two café-au-lait spots.

\section{Associated Complications}

NF can result in disfigurement, especially if the tumors appear on the face or exposed areas of the arms and legs. Scoliosis, or curvature of the spine, when severe, can also affect appearance. Surgery can remove only some tumors and does not prevent the spread of additional tumors.
Learning disabilities and hyperactivity are present in many children and youth with NF. Children with NF-1 have more learning disabilities than their brothers or sisters, and these learning disabilities bear a relationship to abnormalities detected by neuroimaging (Chapman, 1993).

Individuals with NF can have both optic gliomas and acoustic neuromas, which are tumors that can affect vision and hearing. These tumors are usually rare but pose considerable implications for classroom learning. Because of the considerable disfigurement, a child with NF usually needs psychological counseling, and sensitivity training for the classroom teacher and the child's peers is also recommended.

Individuals with NF may also have a large head circumference, which does not usually indicate any significant medical problem. Other complications include congenital defects of bone, high blood pressure, and, more rarely, seizure disorders, itching of the skin, and greater risk for stroke, malignant tumors, fine and gross motor problems, and brain tumors.

\section{Interventions}

Children with NF need medical follow-up to determine the course of their tumors and if surgery is an appropriate option. Other medical complications are typically managed by a pediatric neurologist or referred to other subspecialists. As is the case with other children with complex disorders, a team approach involving numerous medical and ancillary health providers offers the most comprehensive treatment.

Most children with NF are eligible for special education services. In some rare cases a student may be classified as mentally retarded, especially if intracranial tumors are involved. Often special educators, school psychologists, and social workers help remediate the academic and social problems of students with NF. The learning disorder is usually not progressive, and the management of learning disabilities or mental retardation is the same as for other children with similar skill levels.

Considerable research is being conducted on neurofibromatosis. The genes responsible for NF-1 and NF-2 have been mapped, and research is now centering around changing the disease process by altering how the abnormal NF-1 and NF-2 genes act (NF Foundation, 1994). It is hoped that ultimately an effective treatment or cure will result from this work.

\section{Resources}

National Neurofibromatosis Foundation, Inc.

141 Fifth Avenue, Suite 7-S

New York, NY 10010-7105

(212) 460-8980, (800) 323-7938

Fax (212) 529-6094 


\section{SEIZURE DISORDERS}

\section{Definition and Incidence}

Seizures are relatively common in childhood, with approximately $5 \%$ of children having had at least one seizure by the age of 16 (Schweich, 1994). A seizure is defined as a transient change in the level of consciousness or an involuntary alteration of motor activity, sensation, or behavior. A seizure that manifests primarily as repetitive motor activity is referred to as a convulsion. The term epilepsy, or seizure disorder, is used to describe recurrent seizures. The incidence of epilepsy has been reported to range from $0.8 \%$ to $1.1 \%$ (Glaze, 1994).

Seizures generally last from 5 to 15 minutes. If the child has a seizure that is persistent or has recurrent seizures lasting more than 30 minutes in which consciousness is not regained, the child is said to be in status epilepticus (Tunik \& Young, 1992).

Seizures are divided into two major categories, generalized and partial. Generalized seizures are those that involve both hemispheres of the brain; partial seizures involve a limited, or functional, area of one hemisphere. A child may have both types of seizures, referred to as a mixed-seizure disorder (Batshaw \& Perret, 1992).

Another type of frequently occurring seizure is the febrile seizure. A febrile seizure is defined as a convulsion associated with an elevated temperature occurring in a child who is less than 6 years of age (Fishman, 1994). Although febrile seizures occur in $3 \%$ to $4 \%$ of all children, for the majority of children they occur only one time (Freeman, 1992). Because they are generally isolated incidences that are usually outgrown, febrile seizures do not constitute a seizure disorder and are generally not treated.

\section{Causes}

Seizures result from abnormal electrical impulses in the brain. Common causes of seizures include fever, infections (e.g., meningitis, encephalitis), head trauma, metabolic abnormalities (e.g., hypoxia, hypoglycemia), toxic ingestions, and withdrawal of anticonvulsant medications. Miscellaneous other causes include brain tumors and intracranial hemorrhage (Schweich, 1994).

\section{Characteristics}

Two of the most common types of generalized seizures are tonic-clonic and absence. Partial seizures can be divided into simple and complex. The following is a description of individual seizure types.

Generalized tonic-clonic seizures are the most common type of generalized seizure. They are characterized by an abrupt arrest of activity and an immediate loss of consciousness, usu- ally resulting in the child's falling to the ground. During the tonic phase, which generally lasts only a few seconds to a minute, the child is rigid. The clonic phase that follows is characterized by symmetric, rhythmic jerking, and often incontinence. The clonic phase is commonly followed by confusion, lethargy, or sleep. Although lasting longer than the tonic phase, the clonic phase often terminates spontaneously in less than 5 minutes (Glaze, 1994). Generally, these types of seizures only become dangerous when they last for an extended period of time (i.e., more than 30 minutes), in which case they may become life-threatening (Batshaw \& Perret, 1992).

Absence seizures (formerly called petit mal) are characterized by very brief episodes of altered awareness (one or two seconds) during which the child ceases activity and appears to stare blankly (or daydream) without responding to verbal or physical stimuli. These staring epsiodes may be accompanied by subtle motor activity such as eye blinking or slight movements of the arms. Seizures may occur many times a day without the child's being aware of them. Because these seizures are subtle, they are usually not recognized the first time they occur and may not even be noticed until they begin affecting schoolwork.

Simple partial seizures are characterized by sudden, jerking motions, or twitching with no apparent loss of consciousness.

Complex partial seizures (formally called temporal lobe seizures) are characterized by staring episodes and automatisms (e.g., lip smacking, picking at clothes, or wandering in a confused state). These episodes usually last 30 seconds or longer.

A seizure disorder is diagnosed by a history of recurrent seizures. A detailed history, physical examination, and an electroencephalogram (EEG) interpreted by a neurologist who has experience with infants and young children are all helpful in diagnosing a seizure disorder (Glaze, 1994). According to Golden (1992), prolonged EEG-video monitoring to document a correlation between EEG events and the presenting clinical features is accepted as the most definitive method of making a diagnosis of seizures.

Because the diagnosis of a seizure disorder is a clinical process, school personnel can be of assistance by providing a description of the seizures. In fact, the Epilepsy Foundation of America (1987) has emphasized the need for accurate educator observation of seizures. Teachers should use a system for recording seizure activity, such as the Seizure Observation Form developed by Michael (1992), as a way to gain an understanding of the child's seizures.

\section{Associated Complications}

Complications may occur as a result of a seizure or may be due to treatment effects. If the child experiences status epilep- 
ticus, neuronal damage may occur, resulting in permanent cognitive and motor deterioration (Binnie, Channon, \& Marston, 1990). With other types of seizures, complications often occur as a result of treatment. For example, all anticonvulsant medications have some allergic and idiosyncratic side effects (Freeman, 1992), often causing the child to experience adverse behavioral and cognitive effects from taking the drugs. Side effects can frequently be minimized by altering the dose of a given antiepileptic medication or substituting another drug (Glaze, 1994).

Children with epilepsy may have varying degrees of learning difficulties. Aldenkamp, Alpherts, Dekker, and Overweg (1990) reported that children with epilepsy appear to be at higher risk of developing learning problems than the general population. Similarly, Batshaw and Perret (1992) noted that various degrees of mental retardation may be found in approximately $50 \%$ of children with epilepsy (with the other half having normal intelligence). The severity of the learning problem appears to depend on etiology, age at seizure onset, and the type, frequency, and localization of seizures (Dam, 1990). Binnie et al. (1990) stated that epilepsy may interfere with learning by disrupting information processing and hindering the consolidation of information. Further, the drugs taken for seizure control may cause changes in neural functioning.

\section{Interventions}

Seizures are most commonly treated with medication. Such treament follows a comparison between the risks and benefits of treatment and the risks and benefits of remaining off medication. Seizures can be controlled in approximately $70 \%$ of children using antiepileptic medication (Glaze, 1994), most commonly Phenytion (Dilantin), Phenobarbital, Carbamazepine (Tegretol), Ethosuximide (Zarontin), Valproic Acid (Depakene), and Primidone (Mysoline).

In some cases, seizure medication can be gradually discontinued after a period of time, upon recommendation of the physician. For example, Freeman (1992) reported that studies have shown that a child who has been seizure-free for 2 years has a $75 \%$ chance of staying seizure-free off medication. For some children, complete seizure control cannot be obtained, even with the use of medications. In those instances, it is believed that the occurrence of an occasional seizure is preferable to increasing the dosage of medication and risking the side effects from too high of a dosage (Henriksen, 1990).

In addition to medication, an important aspect of seizure treatment involves educating and counseling the child, family, school personnel, and peers about the disorder. Because misconceptions about seizures are common, it is important that the student and those involved with the student clearly understand the child's condition. For example, teachers and school nurses need to know when it is necessary to seek medical attention for a seizure and when medical intervention is not warranted. Glaze (1994) warned that excessive reactions to a student's seizures may diminish self-esteem, raise anxiety levels, and alter social interaction with classmates.

Because learning problems may coexist with a seizure disorder, the child may require special education, under the designation of Other Health Impaired. Because the child may have a range of learning problems, several educational modifications may be necessary to meet the child's unique needs.

\section{Resources}

Epilepsy Foundation of America

4351 Garden City Drive, Suite 406

Landover, MD 2078

(310) $577-0100$

\section{TRAUMATIC BRAIN INJURY}

\section{Definition and Incidence}

The term brain injury is medically defined as trauma to the head with evidence of brain involvement (Rivara, 1994). Traumatic brain injury (TBI) is also educationally defined. The U.S. Department of Education (1992) provides the following definition:

\begin{abstract}
Traumatic brain injury means an acquired injury to the brain caused by an external physical force, resulting in total or partial functional disability or psychosocial impairment, or both, that adversely affects a child's educational performance. The term applies to open or closed head injuries resulting in impairments in one or more areas, such as cognition; language; memory; attention; reasoning; abstract thinking; judgement; problem solving; sensory, perceptual and motor abilities; psychosocial behavior; physical functions; information processing; and speech. The term does not apply to brain injuries that are congenital or degenerative; or brain injuries induced by birth trauma. (p. 44802)
\end{abstract}

It has been estimated that approximately 1 per 500 children is hospitalized annually for traumatic brain injury (Center for Disease Control, 1990). However, the incidence of brain injury may be significantly underreported because not all children who receive brain injuries are taken to the hospital. Instead, parents may take their children to clinics or their pediatrician's office, or they may not seek medical attention at all (especially in cases of abuse). Traumatic brain injury occurs twice as frequently in males as it does in females. 


\section{Causes}

The cause of TBI varies with the child's age. For infants the most common cause is abuse or neglect, whereas for toddlers and preschoolers, falls are a common cause, although abuse also plays a factor. For children in the early elementary grades, falls and pedestrian-motor vehicle accidents are the major cause, while children in the late elementary and middle school grades usually receive TBI as a result of pedestrian-bicycle accidents, pedestrian-motor vehicle accidents, and sports. Finally, motor vehicle accidents are the primary cause of TBI in the high school years (Savage \& Wolcott, 1994).

Injury from head trauma results not only from the initial blow to the head, but also from secondary damage. Primary injury is caused by the stretching, tearing, shearing, and bruising of brain tissue that results from trauma to the head. Primary injury can also include skull fractures, hemorrhage, and hematomas. Secondary injury to the brain may result from increased intracranial pressure, status epilepticus, hypoxia-ischemia, and infection (Kaufman \& Dacey, 1994).

\section{Common Characteristics}

The most common symptom indicating damage to the brain following head trauma is an altered level of consciousness, ranging from lethargy and drowsiness to coma and brain death. The seriousness of a brain injury is indicated by the duration and severity of the coma. The latter is commonly measured by using the Glasgow Coma Scale (GCS) (Teasdale \& Jennette, 1974) at the time of admission to the hospital or emergency room. The GCS is based on the person's eye opening, as well as motor and verbal response. With scores ranging from 3 (worst) to 15 (best), the GCS provides a standardized scoring system for quantifying the level of consciousness (Rosman, 1994). Using the GCS, mild injuries are usually described as those having a score of 13 to 15 , moderate injuries a 9 to 12 , and severe injuries a score of 8 or less.

The severity of a TBI is also judged by the length of posttraumatic amnesia (PTA), defined as the period of disorientation and disturbed memory function that occurs after a TBI (Forrester, Encel, \& Geffen, 1994). The duration of PTA has been found to be a significant indicator of neurobehavioral and functional outcome in children (McDonald et al., 1994). Other diagnostic procedures for determining the extent of brain injury include computed tomography (CT) and magnetic resonance imaging (MRI).

\section{Associated Complications}

Following TBI, children and adolescents may experience a wide range of physical, cognitive, and psychosocial deficits that may improve over time or may be permanent. The magnitude of these deficits appears to be consistently related to the severity of the child's brain injury, with children who have experienced the most severe injuries demonstrating the greatest deficits (Jaffe et al., 1992). Most long-term follow-up studies have focused on 1- to 5-year outcomes (Massagli \& Jaffe, 1994), but problems may persist for much longer. For example, in a follow-up study of persons who had sustained head injuries as children, Klonoff, Clark, and Klonoff (1993) found that $31 \%$ of the persons still reported persistent cognitive and emotional problems 23 years later. The following is a review of some of the common sequelae following TBI.

\section{Physical Sequelae}

The physical effects of TBI include motor problems, reduced stamina, seizures, and sensory deficits. Motor problems such as hemiparesis, rigidity, spasticity, tremors, and apraxia are most common in the early stages and often improve rapidly. More subtle motor impairments, such as reduced speed of motor performance, have been found to be persistent, however (Chaplin, Deitz, \& Jaffe, 1993). Fatigue is another common complaint of children following TBI, with reduced stamina lasting as long as a year (Lezak, 1983).

The child may also experience seizures following head trauma. According to Kennedy and Freeman (1986), studies have shown that $5 \%$ to $9 \%$ of children experience seizures within the first week after trauma and approximately $2 \%$ develop late posttraumatic epilepsy. These seizures are generally treated with anticonvulsant medication, which may even be given on a prophylactic basis in an attempt to prevent seizures.

Sensory deficits following a TBI include hearing and vision problems. Because the ear is commonly damaged during a brain injury, a hearing loss can occur. Visual problems include double vision and visual-field defects, which usually improve over time (Chamovitz, Chorazy, Hanchett, \& Mandella, 1985).

\section{Cognitive Sequelae}

Long-term cognitive problems that may occur following a TBI include memory deficits, reduced intellectual functioning, language impairments, and reduced academic functioning. Levin and Eisenberg (1979) found that, among these, memory impairment was the most common cognitive deficit. Additionally, children who experience severe brain injury usually suffer a decline of intellectual functioning following the accident (Jaffe et al., 1992). However, progressive improvements in measured intelligence for up to five years following the injury have been noted (Klonoff, Low, \& Clark, 1977). 
Early communication problems related to motor-speech function tend to recover rather rapidly, creating the impression of normal communicative functioning. However, longterm communication challenges relate to the socially skilled application of available speech and language skills (Ylvisaker, 1993).

With regard to academic functioning, a number of problems may interfere with the child's performance. These problems typically include lack of attention and concentration, heightened distractibility, short-term memory impairments, problems with judgment and reasoning, cognitive inflexibility, and impaired problem-solving ability (Massagli \& Jaffe, 1994).

\section{Psychosocial Sequela}

Psychosocial problems occurring after a TBI may be directly related to damage to the brain or an exacerbation of preinjury behavior difficulties, or may occur as a reaction to posttraumatic cognitive deficits (Deaton \& Waaland, 1994). Common behavior problems include distractibility/poor concentration, poor anger control, irritability, low frustration tolerance, aggression, anxiety, and hyperactivity (Michaud, Rivara, Jaffe, Fay, \& Dailey, 1993).

\section{Interventions}

Initial intervention during the acute stages of TBI consists of medical management of the child. Acute treatment includes maintaining ventilation and circulation; surgically treating epidural and subdural hematomas and depressed skull fractures; and controlling intracranial pressure (Kaufman \& Dacey, 1994).

After the child has been medically stabilized, inpatient rehabilitation usually consists of physical, occupational, and speech therapies aimed at improving the child's functioning and independence. During this time, planning for school reentry should begin. A comprehensive re-entry program includes a designated person or team responsible for the interchange of information between hospital and school; education of families about TBI; and preparation of school personnel for the re-entering child (Mira \& Tyler, 1991).

Children with TBI may require special education services because of their long-term physical, cognitive, and psychosocial difficulties. Because these children demonstrate a wide range of associated deficits, a full continuum of educational services is required, ranging from homebound services to placement in the general education classroom with modifications. Determining the exact needs of the student with TBI requires a comprehensive assessment involving strategies and methods that differ from the usual special education testing
(Mira, Tucker, \& Tyler, 1992). This includes a neuropsychological examination conducted by an evaluator who has experience with students with TBI.

Once the student's needs have been assessed, school personnel can develop a program to meet his or her unique needs. Specific strategies include teaching the child compensatory strategies to aid memory, shortening the length of the school day to reduce fatigue, extending the school year to prevent academic regression, and providing ample time for task completion to compensate for delayed processing (Tyler \& Myles, 1991). In addition, behavior change strategies can be employed to help decrease specific behavior problems and help increase adaptive skills such as initiation and socialization (Deaton, 1994).

Because the children who have suffered TBI have rapidly changing needs, educational modifications must be reviewed frequently (Tyler \& Mira, 1993). During the first year, this may include reviewing and modifying the individualized education program (IEP) goals and objectives as frequently as every 30 days.

Besides interventions that take place after a TBI, interventions should be aimed at preventing TBI. Brain injuries do not occur at random (Rivara, 1994); most are preventable. Specific strategies include changes in behavior such as wearing a helmet during sports and recreational activities such as riding bicycles, skateboarding, and roller blading; using safety belts and car seats; and avoiding alcohol while operating a motor vehicle. Passive strategies should be used as well. These involve making the environment safer for children by ensuring that playground surfaces are more energy absorbent, building cars with airbags, and improving traffic safety.

\section{Resources}

National Head Injury Foundation, Inc.

1776 Massachusetts Ave., Suite 100

Washington, DC 20036

(200) 296-NHIF

\section{TURNER SYNDROME}

\section{Definition and Incidence}

Turner syndrome is a chromosomal disorder in which a complete chromosome, the Y chromosome, is missing. Because this chromosome is responsible for the development of the male sexual organs, all children with Turner syndrome are female. The incidence of Turner syndrome is estimated at 1 in 2,500 to 1 in 6,000 live female births. About $20 \%$ of spon- 
taneous abortions have the Turner chromosomal difference (Smith, 1989).

\section{Cause}

Turner syndrome is the result of a partial or complete deletion of one $\mathrm{X}$ chromosome (XO). It provides an example of a child born with an abnormal number of either or both the $\mathrm{X}$ and $\mathrm{Y}$ chromosomes. This syndrome was first reported by physicians after seeing girls in their late teens who had not begun to menstruate. It can now be detected by chromosomal analysis.

\section{Characteristics}

Many children with Turner syndrome have only minimal differences in appearance. These can include short stature (adult height less than 56 inches), broad chest with widely spaced nipples, webbed posterior neck (about 50\%), low posterior hairline, short neck, increased carrying angle of arms, abnormal ears, epicanthal folds, ptosis of the upper eyelids, downward and outward slant of palpebral fissures, short fourth metacarpals, and sexual infantilism in postpuberty (all girls with Turner syndrome will be infertile).

In addition, congenital heart disease occurs in $15 \%$ to $30 \%$ and hypertension in another $25 \%$ of the cases. Hearing loss is found in $50 \%$ of the cases, with various renal abnormalities in another 50\%. Thyroid and kidney problems are also common. The prognosis is good for a normal lifespan if cardiovascular abnormalities and hypertension are absent.

\section{Associated Complications}

Girls with Turner syndrome typically exhibit spatial deficits and neuromuscular impairments, resulting in extreme difficulty with mathematics and perceptual organization. As a result, they may become lost easily due to directionality problems, work slowly (especially when copying from the board or a text), and have poor handwriting (Bender, Puck, Salbenblatt, \& Robinson, 1986). They may also exhibit hyperactivity as well as attention deficit disorder. Further, they have difficulty discriminating affect from facial expression (McCauley, Kay, Ito, \& Treader, 1987), have difficulty recognizing faces, and appear socially immature.

\section{Intervention}

Girls with Turner syndrome need medical follow-up since estrogen therapy has been shown to alleviate some physical problems, although it does not alter the concomitant cognitive differences (Waber, 1979). Despite a wide variety of aca- demic skill levels, most girls with Turner syndrome do not have mental retardation. Many students, though, need special education services for specific learning disabilities in mathematics and perceptual and social skills. These students will also need counseling to discuss their inability to bear children, especially when exposed to a comprehensive health curriculum that includes sexuality issues.

\section{Resources}

Turner Syndrome Society of the United States

15500 Wayzata Blvd., Suite 768-214

Wayzata, MN 55391

(612) 475-9944

Fax (612) 475-9949

\section{CONCLUSION}

The disabilities reviewed here are just a few among the wide variety of disabilities that are being seen more frequently in the educational system because of recent advances in medical technology and diagnostic procedures. Given the unique and diverse needs of this expanding population of students, comprehensive services from a variety of professionals are required. Because many of these disabilities are medically based, educators will need to work closely with medical personnel, therapists, and parents. Also, there is a clear need for collaborative planning between pediatricians and special educators in school districts (Purvis \& Whelan, 1992) as well as ongoing input from both the family and the medical team (Sexson \& Madan-Swain, 1993) to develop comprehensive educational programs for these students. A basic understanding of the unique needs of each of these pediatric disabilities is the first step toward ensuring that appropriate services are provided.

\section{REFERENCES}

Accardo, P. J., Blondis, T. A., \& Whitman, B. Y. (1991). Attention deficit disorders and hyperactivity in children. New York: Marcel Dekker, Inc.

Aldenkamp, A. P., Alpherts, W. C. J., Dekker, M. J. A., \& Overweg, J. (1990). Neuropsychological aspects of learning disabilities in epilepsy. Epilepsia, 31(Suppl. 4), S9-S20.

American Psychiatric Association. (1980). Diagnostic and statistical manual (3rd ed.). Washington, DC: Author.

American Psychiatric Association. (1987). Diagnostic and statistical manual (3rd ed., rev.). Washington, DC: Author.

American Psychiatric Association. (1994). Diagnostic and statistical manual (4th ed.). Washington, DC: Author.

Barkley, R. (1990). Attention deficit hyperactivity disorder: A handbook for diagnosis and treatment. New York: Guilford Press.

Batshaw, M. L., \& Perret, Y. M. (1992). Seizure disorders. In M. L. Batshaw \& Y. M. Perret (Eds.), Children with disabilities: A medical primer (3rd ed., pp. 489-523). Baltimore: Paul H. Brooks. 
Bender, B. G., Puck, M. H., Salbenblatt, J. A., \& Robinson, A. (1986). Cognitive development of children with sex chromosome abnormalities. In S. D. Smith (Ed.), Genetics and learning disabilities (pp. 175-201). San Diego: College Hill Press.

Binnie, C. D., Channon, S., \& Marston, D. (1990). Learning disabilities in epilepsy: Neurophysiological aspects. Epilepsia, 31(Suppl. 4), S2-S8.

Brown, R. T. (1993). An introduction to the special series on pediatric chronic illness. Journal of Learning Disabilities, 26(12), 4-6.

Brown, R. T., \& Madan-Swain, A. (1993). Cognitive, neuropsychological, and academic sequelae in children with leukemia. Journal of Learning Disabilities, 26(2), 74-90.

Butler, R. W., \& Copeland, D. R. (1993). Neuropsychological effects of central nervous system prophylactic treatment in childhood leukemia: Methodological considerations. Journal of Pediatric Psychology, 18(3), 319-338.

Center for Disease Control. (1990). Childhood injuries in the United States. American Journal of Diseases of Children, 144(6), 627-646.

Chamovitz, I., Chorazy, A. J. L., Hanchett, J. E., \& Mandella, P. A. (1985). Rehabilitative medical management. In M. Ylvisaker (Ed.), Head injury rehabilitation: Children and adolescents (pp. 383-409). San Diego: College Hill Press.

Chaplin, D., Deitz, J., \& Jaffe, K. M. (1993). Motor performances in children after traumatic brain injury. Archives of Physical Medicine and Rehabilitation, 74(2), 161-164.

Chapman, C. A. (1993). Learning disabilities and neurofibromatosis 1: A report. Neurofibromatosis Newsletter, 15(2), 6-8.

Copeland, D. R., Dowell, R. E., Jr., Fletcher, J. M., Bordeaux, J. D., Sullivan, M. P., Jaffe, N., Frankel, L. S., Ried, H. L., \& Cangir, A. (1988). Neuropsychological effects of childhood cancer treatment. Journal of Child Neurology, 3(1), 53-62.

Cummins, S. K., Nelson, K., Grether, J. K., \& Velie, E. M. (1993). Cerebral palsy in four northern California counties, births 1983 through 1985. The Journal of Pediatrics, 123(2), 230-237.

Dam, M. (1990). Children with epilepsy: The effect of seizures, syndromes, and etiological factors on cognitive functioning. Epilepsia, 31(Suppl. 4), S26-S29.

Deaton, A. V. (1994). Changing the behaviors of students with acquired brain injuries. In R. C. Savage \& G. F. Wolcott (Eds.),_Educational dimensions of acquired brain injury (pp. 257-275). Austin, TX: PRO-ED.

Deaton, A. V., \& Waaland, P. (1994). Psychosocial effects of acquired brain injury. In R. C. Savage \& G. F. Wolcott (Eds.),Educational dimensions of acquired brain injury (pp. 239-255). Austin, TX: PRO-ED.

Eicher, P. S., \& Batshaw, M. L. (1993). The child with developmental disabilities: Cerebral palsy. Pediatric Clinics of North America, 40(3), $537-551$.

Epilepsy Foundation of America. (1987). The teacher's role: Children and epilepsy: A guide for school personnel (rev. ed.). Landover, MD: Author.

Fernbach, D. J. (1994). Neoplastic diseases: General considerations. In F. A. Oski, C. D. DeAngelis, R. D. Feign, J. A. McMillan, \& J. B. Warshaw (Eds.), Principles and practice of pediatrics (2nd ed., pp. 678-679). Philadelphia: J. B. Lippincott.

Fishman, M. A. (1994). Febrile seizures. In F. A. Oski, C. D. DeAngelis, R. D. Feign, J. A. McMillan, \& J. B. Warshaw (Eds.), Principles and practice of pediatrics (2nd ed., pp. 2058-2061). Philadelphia: J. B. Lippincott.

Forrester, G., Encel, J., \& Geffen, G. (1994). Measuring post-traumatic amnesia (PTA): An historical review. Brain Injury, 8(2), 175-184

Fowler, M. (1992). C.H.A.D.D. educator's manual. Plantation, FL: CASET Associates, Ltd.

Freeman, J. M. (1992). What have we learned from febrile seizures? Pediatric Annals, 21(6), 355-360.

Glaze, D. G. (1994). Epilepsy. In F. A. Oski, C. D. DeAngelis, R. D. Feign, J. A. McMillan, \& J. B. Warshaw (Eds.),_Principles and practice of pediatrics (2nd ed., pp. 2048-2057). Philadelphia: J. B. Lippincott.

Golden, G. S. (1987). Static encephalopathies. In Textbook of pediatric neurology (pp. 75-85). New York: Plenum Medical.
Golden, G. S. (1992). Nonepileptic paroxysmal events in childhood. Pediatric Clinics of North America, 39(4), 715-725.

Goldson, E. (1993). The medically fragile infant. In M. Krajicek \& R. Tompkins (Eds.), The medically fragile infant (pp. 1-11). Austin, TX: PROED.

Grether, J. K., Nelson, K. B., \& Cummins, S. K. (1993). Twinning and cerebral palsy: Experience in four northern California counties, births 1983 through 1985. Pediatrics, 92(6), 854-858.

Hagberg, B., \& Hagberg, G. (1984). Prenatal and perinatal risk factors in a survey of 681 Swedish cases. In F. Stanley \& E. Alberman (Eds.), The epidemiology of the cerebral palsied (pp. 116-134). Phildelphia: J. B. Lippincott.

Hagerman, R. J. (1987). Fragile X syndrome. Current Problems in Pediatrics, $17,621-674$

Henriksen, O. (1990). Education and epilepsy: Assessment and remediation. Epilepsia, 31(Suppl. 4), S21-S25.

Jaffe, K. M., Fay, G. C., Polissar, N. L., Martin, K. M., Shurtleff, H., Rivara, J. M., \& Winn, H. R. (1992). Severity of pediatric traumatic brain injury and early neurobehavioral outcome: A cohort study. Archives of Physical Medicine and Rehabilitation, 73(6), 540-547.

Kanda, T., Yuge, M., Yamori, Y., Suzuki, J., \& Fukase, H. (1984). Early physiotherapy in the treatment of spastic diplegia. Developmental Medicine and Child Neurology, 26(4), 438-444.

Kaufman, B. A., \& Dacey, R. G. (1994). Acute care management of closed head injury in childhood. Pediatric Annals, 23(1), 18-28.

Kazak, A. E. (1993). Editorial: Psychological research in pediatric oncology. Journal of Pediatric Psychology, 18(3), 313-318.

Kennedy, C. R., \& Freeman, J. M. (1986). Posttraumatic seizures and posttraumatic epilepsy in children. Journal of Head Trauma Rehabilitation, $1(4), 66-73$.

Klonoff, H., Clark, C., \& Klonoff, P. S. (1993). Longterm outcome of head injuries: A 23-year follow-up study of children with head injuries. Journal of Neurology, Neurosurgery, and Psychiatry, 56, 410-415.

Klonoff, H., Low, M. D., \& Clark, C. (1977). Head injuries in children: A prospective five year follow up. Journal of Neurology, Neurosurgery, \& Psychiatry, 40, 1211-1219.

Kurtz, L. A. (1992). Cerebral palsy. In M. L. Batshaw \& Y. M. Perret (Eds.), Children with disabilities: A medical primer (3rd ed., pp. 441-469). Baltimore: Paul H. Brooks.

Levin, H. S., \& Eisenberg, H. M. (1979). Neuropsychological impairment after closed head injury in children and adolescents. Journal of Pediatric Psychology, 4, 389-402.

Lezak, M. D. (1983). Neuropsychological assessment. New York: Oxford University Press.

Mahoney, D. H. (1994). Acute lymphoblastic leukemia in childhood. In F. A Oski, C. D. DeAngelis, R. D. Feign, J. A. McMillan, \& J. B. Warshaw (Eds.), Principles and practice of pediatrics (2nd ed., pp. 679-686). Philadelphia: J. B. Lippincott.

Massagli, T. L., \& Jaffe, K. M. (1994). Pediatric traumatic brain injury: Prognosis and rehabilitation. Pediatric Annals, 23(1), 29-36.

McCauley, E., Kay, T., Ito, J., \& Treder, R. (1987). The Turner syndrome: Cognitive deficits, affective discrimination, and behavior problems. Child Development, 58, 464-473.

McDonald, C. M., Jaffe, K. M., Fay, G. C., Polisar, N. L., Martin, K. M., Liao, S., \& Rivara, J. B. (1994). Comparison of indices of traumatic brain injury severity as predictors of neurobehavioral outcome in children. Archives of Physical Medicine and Rehabilitation, 75(3), 328-337.

Meadows, A., \& Silber, J. (1985). Delayed consequences of therapy for childhood cancer. Cancer Journal for Clinicians, 35(3), 271-286.

Michael, R. J. (1992). Seizures: Teacher observations and record keeping. Intervention in School and Clinic, 27(4), 211-214.

Michaud, L. J., Rivara, F. P., Jaffe, K. M., Fay, G., \& Dailey, J. L. (1993). Traumatic brain injury as a risk factor for behavioral disorders in children. Archives of Physical Medicine and Rehabilitation, 74(4), 368-375.

Mira, M. P., Tucker, B. F., \& Tyler, J. S. (1992). Traumatic brain injury in children and adolescents: A sourcebook for teachers and other school personnel. Austin, TX: PRO-ED. 
Mira, M. P., \& Tyler, J. S. (1991). Students with traumatic brain injury: Making the transition from hospital to school. Focus on Exceptional Children, 23(5), 1-12.

Mitchell, E. A., Aman, M. G., Turbott, S. H., \& Manku, M. (1987). Clinical characteristics and serum essential fatty acid levels in hyperactive children. Clinical Pedicatrics, 26, 406-411.

Munir, K., Biederman, J., \& Knee, D. (1987). Psychiatric comorbidity in patients with attention deficit disorder: A controlled study. Journal of the American Academy of Child and Adolescent Psychiatry, 26, 844-848.

Naeye, R. L., Peters, E. C., Bartholomew, M., \& Landis, R. (1989). Origins of cerebral palsy. American Journal of Diseases of Children, 143(10), $1154-1161$.

National Neurofibromatosis Foundation. (1994). Questions and answers. New York: Author.

Percy, A. K. (1994). Static encephalopathy. In F. A. Oski, C. D. DeAngelis, R. D. Feign, J. A. McMillan, \& J. B. Warshaw (Eds.), Principles and practice of pediatrics (2nd ed., pp. 2025-2028). Philadelphia: J. B. Lippincott.

Prouty, L. A., Rogers, C., \& Stevenson, R. E. (1988). Fragile X syndrome: Growth, development, and intellectual functioning. American Journal of Medical Genetics, 30, 123-142.

Purvis, P., \& Whelan, R. J. (1992). Collaborative planning between pediatricians and special educators. Pediatric Clinics of_North America, 39(3), 451-469.

Reiss, A. L., \& Freund, L. (1990). Fragile X syndrome. Biological Psychiatry, 27, 223-240.

Riccardi, V. M. (1994). The phakomatoses and other neurocutaneous syndromes. In F. A. Oski, C. D. DeAngelis, R. D. Feign, J. A. McMillan, \& J. B. Warshaw (Eds.), Principles and practice of pediatrics (2nd ed., pp. 2128-2134). Philadelphia: J. B. Lippincott.

Riccio, C., Hynd, G., Cohen, M., \& Gonzalez, J. (1993). Neurological basis of attention deficit hyperactivity disorder. Exceptional Children, 60(2), $108-117$.

Rivara, F. P. (1994). Epidemiology and prevention of pediatric traumatic brain injury. Pediatric Annals, 23(1), 12-17.

Rosman, N. P. (1994). Acute head trauma. In F. A. Oski, C. D. DeAngelis, R. D. Feign, J. A. McMillan, \& J. B. Warshaw (Eds.), Principles and practice of pediatrics (2nd ed., pp. 2038-2048). Philadelphia: J. B. Lippincott.

Ross, D. M., \& Ross, S. A. (1982). Hyperactivity: Current issues, research, and theory (2nd ed.). New York: Wiley.

Santos, K. E. (1992). Fragile X syndrome: An educator's role in identification, prevention, and intervention. Remedial and Special Education, 13(2), 32-39.

Savage, R. C., \& Wolcott, G. F. (1994). Overview of acquired brain injury. In R. C. Savage \& G. F. Wolcott (Eds.),Educational dimensions of acquired brain injury (pp. 3-12). Austin, TX: PRO-ED.

Schweich, P. J. (1994). Emergency medicine except poisoning. In F. A. Oski, C. D. DeAngelis, R. D. Feign, J. A. McMillan, \& J. B. Warshaw (Eds.), Principles and practice of pediatrics (2nd ed., pp. 827-829). Philadelphia: J. B. Lippincott.

Sexson, S. B., \& Madan-Swain, A. (1993). School reentry for the child with chronic illness. Journal of Learning Disabilities, 26(2), 115-125.

Shapiro, B. K. (1992). Normal and abnormal development: Mental retardation. In M. L. Batshaw \& Y. M. Perret (Eds.), Children with disabilities: A medical primer (3rd ed., pp. 259-290). Baltimore: Paul H. Brooks.

Shapiro, B. K., \& Capute, A. J. (1994). Cerebral palsy. In F. A. Oski, C. D. DeAngelis, R. D. Feign, J. A. McMillan, \& J. B. Warshaw (Eds.), Prin- ciples and practice of pediatrics (2nd ed., pp. 679-686). Philadelphia: J. B. Lippincott.

Sherman, S. L. (1991). Épidemiology. In R. J. Gagerman \& A. Cronister-Silverman (Eds.), The fragile $X$ syndrome: Diagnosis, treatment, and research (pp. 634-646). Baltimore: Johns Hopkins University Press.

Smith, D. D., \& Luckasson, R. (1992). Introduction to special education: Teaching in an age of challenge. Needham Heights, MA: Allyn and Bacon.

Smith, S. M. (1989). Congenital syndromes and mildly handicapped students: Implications for special educators. Remedial and Special Education, 10(3), 20-30.

Stainback, W., \& Stainback, S. (1989). Educating all students in the mainstream of regular education. Baltimore: Paul $\mathrm{H}$. Brookes.

Still, G. F. (1902). The Coulstonian lectures on some abnormal physical conditions in children. Lancet, 1008-1012.

Szatmari, P., Offord, D. R., \& Boyle, M. H. (1989). Ontario child health study: Prevalence of attention deficit disorder with hyperactivity. Journal of Child Psychology and Psychiatry, 30, 219-230.

Teasdale, G., \& Jennette, B. (1974). Assessment of coma and impaired consciousness: A practical scale. Lancet, 2, 81-84.

Theobald, T. M., Hay, D. A., \& Judge, C. (1987). Individual variations and specific cognitive deficits in the fragile $\mathrm{X}$ syndrome. American Journal of Human Genetics, 28, 1-11.

Tunik, M. G., \& Young, G. M. (1992). Status epilepticus in children: The acute management. Pediatric Clinics of North America, 39(5), 1007-1024.

Tunnessen, W. W. (1994). Common syndromes with morphologic abnormalities. In F. A. Oski, C. D. DeAngelis, R. D. Feign, J. A. McMillan, \& J. B. Warshaw (Eds.), Principles and practice of pediatrics (2nd ed., pp. 2176-2200). Philadelphia: J. B. Lippincott.

Turnbull, J. D. (1993). Early intervention for children with or at risk of cerebral palsy. American Journal of Diseases of Children, 147(1), 54-59.

Tyler, J. S., \& Mira, M. P. (1993). Educational modifications for students with head injuries. Teaching Exceptional Children, 25(3), 24-27.

Tyler, J. S., \& Myles, B. S. (1991). Serving students with traumatic brain injury: A new challenge for teachers of students with learning disabilities. LD Forum, 16(1), 69-74.

United Cerebral Palsy Associations. (1993). Cerebral palsy: Facts and figures. Washington, DC: Author.

U.S. Department of Education. (1991). Policy memorandum on ADD. Washington, DC: Author.

U.S. Department of Education. (1992, September 29). Rules and regulations. Federal Register, 57(189), 44802. Washington, DC: U.S. Government Printing Office.

Waber, D. P. (1979). Neuropsychological aspects of Turner syndrome. Developmental Medicine and Child Neurology, 21, 58-70.

Warshaw, J. B. (1992). Intrauterine growth restriction revisited. Growth, Genetics, and Hormones, 8(5), 123-129.

Wolf-Schein, E. G., Sudhalter, V., \& Cohen, I. L. (1987). Speech-language and the fragile X syndrome: Initial findings. ASHA, 29, 35-38.

Ylvisaker, M. (1993). Communication outcome in children and adolescents with traumatic brain injury. Neuropsychological Rehabilitation, 3(4), 367-387.

The information presented in this article was funded in part by the following grants: Kansas State Board of Education Title VI-B Grant Project Number 9125-FY94 and Federal Government Grant Number H029K10061-94.

PERMISSIONS AND COPYRIGHT • All rights are reserved. No part of this publication may be reproduced, photocopied, faxed, stored in a retrieval system, or transmitted, in any form or by any means, electronic, mechanical, recording or otherwise, without the prior written permission of the publisher. $\bullet$ Back issues are available for sale. $\bullet$ Reproduction requires permission and payment of fees. It is illegal and a violation of federal copyright law to reproduce this publication without permission. Direct all inquiries to the permissions editor. 